\title{
Almanaque On The Rocks: revitalizando um tema e um formato esgotado*
}

\section{Almanaque On The Rocks: revitalizing a sold out theme and format}

Clarice da Nóbrega Barreto ${ }^{1}$ Débora Simões Teixeira Mourão² Ursula Betina Diesel ${ }^{3}$
* Recebido em: $26 / 03 / 2015$. Aprovado em: 13/04/2015.

1 Graduada em Comunicação Social com habilitação em Publicidade e Propaganda pelo Centro Universitário de Brasília - UniCEUB. (2015). E-mail: claricenobregab@gmail.com

2 Graduada em Comunicação Social com habilitação em Publicidade e Propaganda pelo Centro Universitário de Brasília - UniCEUB. (2015).E-mail: debby_simoes@hotmail.com

3 Mestre em Comunicação Social com enfoque em Semiótica, pela UNISINOS - Universidade do Vale do Rio dos Sinos (RS). Docente no curso de Publicidade e Propaganda no UniCEUB. E-mail: ursula.diesel@uniceub.br.

\section{Resumo}

Este artigo consiste em um projeto experimental de um almanaque sobre as curiosidades de astros do rock, nacionais e internacionais, e tem como objetivo apresentar a possibilidade de trabalhar formato de publicação já bastante utilizado e que, por isso, estaria esgotado, a partir de um tema muito explorado, o estilo musical rock. A maneira escolhida para revitalizar o almanaque foi disponibilizá-lo em meio digital e tornar a experiência do leitor mais dinâmica e interativa, por meio de hyperlinks para outras publicações, músicas etc. Enquanto isso, apesar de o rock estar presente em biografias e diversos websites dedicados a artistas, ele não é abordado em uma publicação voltada especificamente para bandas escolhidas com base em pesquisa de campo que defina sobre quais artistas o público-alvo do produto quer saber. Além disso, um produto de comunicação deve ser elaborado de maneira que as escolhas gráficas dialoguem com o tema abordado e também possam ser justificadas em relação ao seu público; características que o Almanaque On The Rocks traz.

Palavras-chave: Almanaque. Rock. Meio digital. Interatividade. Design editorial.

\begin{abstract}
This paper consists in an experimental project of an almanac about curiosities of rock stars, national and international, and has as objective showing the possibility of working a format of publication already heavily utilized and therefore out-of-print, from a highly explored theme, rock. The chosen way to revival the almanac was to make it available through digital media and transforming the experience of the reader more dynamic and interactive, through hyperlinks to others publications, music, etc. Meanwhile, although rock is present in biographies and diverse websites dedicated to artists, it isn't addressed in a publication specifically about bands that are chosen from a field research that defines which artists the target audience of the product wants to know about. Besides that, a communication product must be elaborated in a way that the graphic choices speak to the addressed theme and can also be justified by the audience; characteristics that Almanaque On The Rocks has.
\end{abstract}

Keywords: Almanac. Rock. Digital media. Interactivity. Editorial design. 


\section{Introdução}

O rock está se desgastando e esse estilo musical parece ter perdido seu apelo. Apesar de haver grande quantidade de websites e publicações voltadas ao tema, eles tratam o assunto do mesmo modo, focando na música em si e não no contexto pessoal da banda, como a biografia dos integrantes, curiosidades sobre turnês, shows etc.

Já o almanaque, apesar de não ter previsão tão negativa quanto ao rock, está em momento complicado de transição para o digital assim como outros tipos de publicação comumente trazidas apenas em formato impresso ${ }^{4}$.

Pensando no público que não tem muito contato com o rock, e que não participou dos anos dourados do almanaque impresso, este artigo busca revelar o caminho percorrido para conseguir criar um almanaque digital que contenha textos curtos e históricos com curiosidades sobre bandas de rock selecionadas, apresentadas de forma cronológica e representadas por meio de fotografias. Tudo para alcançar o objetivo principal que consiste em “dar nova roupagem" numa temática que está saturada, por meio de nova linha de abordagem e trazer as características do formato tradicional do almanaque para o digital, de maneira atrativa para seus leitores. Revitalizando, assim, o tema e o formato almanaque.

Para iniciar o trabalho, foram realizadas entrevistas com pessoas relacionadas ao mercado editorial (Fabio Volpe, diretor de redação do Almanaque Abril e Kid Vinil e Ana Bahiana, jornalistas e autores de almanaque), o que permitiu a sondagem do ambiente em que o produto seria posicionado. $\mathrm{O}$ segundo passo na metodologia foi realizar uma pesquisa de campo com 35 pessoas, entre elas musicistas e um professor de música, com idade entre 15 e 75 anos, que gostassem ou não de rock. Os pesquisados tiveram que falar o nome das cinco primeiras bandas de rock que lhes viessem à cabeça, as cinco top of mind, totalizando 85 bandas não repetidas. Destas, foram selecionadas as bandas que obtiveram dois votos ou mais, resultando em 20 bandas.

Após conseguir definir que caminho percorrer, foi realizada pesquisa bibliográfica para conseguir trazer todo o embasamento teórico e conceitual necessário para fortalecer as escolhas feitas na publicação.

4 Informação retirada de entrevista realizada com Fabio Volpe, diretor de redação do Almanaque Abril.
Reunindo todas as informações necessárias para começar a produção do almanaque, a primeira decisão a ser tomada consistiu no meio que hospedaria o produto. A escolha foi o website Issuu ${ }^{5}$, a maior plataforma digital presente no mercado atual totalmente voltada para publicações online - existem mais de 21 milhões de publicações no website. 15 mil novas publicações são colocadas na plataforma a cada dia $^{6}$.

\section{Mercado editorial}

O mercado editorial abrange todo os tipos de publicações, sejam impressas ou digitais, desde revistas em quadrinhos a Bíblias. No Brasil, esse setor se expande cada vez mais; o número de títulos produzidos e de exemplares vendidos cresce de maneira contínua a cada ano, tendo apresentado faturamento de $\mathrm{R} \$ 5.359 .426 .184,63$ no ano de $2013^{7}$ (SINDICATO NACIONAL DOS EDITORES DE LIVROS; 2013).

Apesar de haver outras diversas formas de leitura (computadores, tablets, smartphones) cada vez mais populares, os impressos ainda têm enorme espaço no mercado, com aumento no número de títulos e vendas de periódicos e revistas especializadas. Segundo Haslam (2006, p. 12), "o mercado da informação parece estar em eterna expansão, e a nova tecnologia de leitura na internet está ampliando - no lugar de substituir - o consumo de seu primo mais velho, o livro".

No entanto, a dispensabilidade de impressão do livro ou de uma publicação permite que o autor, designer, diagramador possam fazer escolhas mais livres no formato deste, podendo integrar à sua publicação elementos de interação, como música, hyperlinks para outras publicações, websites, glossários. Além disso, os digitais, ao contrário dos impressos, não ocupam espaço físico e têm ao seu lado a enorme capacidade de armazenamento do meio digital.

Os almanaques são exemplos de publicações que podem ser encontradas tanto em formato impresso como digital. O almanaque é uma publicação, normalmente anual, que traz curiosidades, fatos, textos históricos e

$<$ http://issuu.com>.

Disponível em: <http://issuu.com/about $>$. Acesso em: 27 abr. 2015.

7 Disponível em: <http://www.snel.org.br/dados-do-setor/producao-e-vendas-do-setor-editorial-brasileiro/>. Acesso em: 26 abr. 2015. 
imagens que marcam determinadas datas, dispostas em ordem cronológica, num formato de linha do tempo.

Segundo o Grande Dicionário Houaiss da Língua Portuguesa (2012), alguns significados de almanaque são: "calendário com os dias e os meses do ano, os feriados, as luas, as festas etc.; folhinha"; "folheto ou livro que, além do calendário do ano, traz diversas indicações úteis, poesias, trechos literários, anedotas, curiosidades etc." e "edição especial, mais volumosa, de revistas (esp. de histórias em quadrinhos), de publicação esporádica ou periódica”.

No Brasil, um dos almanaques mais famosos e respeitados é o Almanaque Abril. Publicado anualmente em versão impressa e online pela Editora Abril desde 1974, ele contém fatos e dados de referência, conceitos, definições, curiosidades, mapas etc., além dos mais importantes acontecimentos da atualidade ${ }^{8}$, sendo fonte confiável de pesquisa, uma vez que os dados nele presentes são obtidos em fontes primárias de informação, como o IBGE e as agências da ONU, e são traduzidos para uma linguagem adequada aos leitores ${ }^{9}$.

Já o Popcorn, almanaque dos Filmes do Rock do crítico de música Garry Mulholland, conta com apresentação de Kid Vinil e está disponível em formato impresso e e-book, e traz filmes que abordam o rock, como Grease, Footloose, Jailhouse Rock, a partir dos anos 50. Além do e-book, é possível acessar uma prévia do almanaque (cerca de 31 páginas) disponível no Issuu ${ }^{10}$, no perfil do Grupo Editorial Pensamento, responsável pela editora Seoman, que publicou o almanaque (MULHOLLAND, 2011).

Para que seja possível a criação de um almanaque, impresso ou em formato digital, é necessária extrema atenção ao projeto gráfico em que toda a diagramação da publicação será decidida, como que tipografia, cores etc. serão usadas.

De acordo com Warde (1955 apud HENDEL, 2003 , p. 28), quando alguém bebe vinho num copo que possui design extravagante, presta mais atenção no copo em si do que na bebida em seu interior. A autora leva essa

8 Disponível em: <http://www.publiabril.com.br/marca/almanaqueabril/revista/informacoes-gerais $>$. Acesso em: 26 abr. 2015.

9 Informação retirada da entrevista com Fabio Volpe, diretor de redação do Almanaque Abril.

10 Disponível em: <http://issuu.com/grupoeditorialpensamento/docs/popcorn>. Acesso em: 26 abr. 2015. ideia para o mundo da tipografia afirmando que, quando o tipo usado é muito extravagante e trabalhado de um jeito fora do comum, as pessoas imediatamente param de prestar atenção na mensagem passada e focam somente no que o design está passando. Logo, a tipografia estaria se intrometendo entre o autor e o leitor. Nesse tipo de texto, a tipografia não pode chamar mais atenção que o assunto abordado. Além disso, é necessário escolher um tipo que seja legível e não canse a visão, independentemente da classe tipográfica em que ele se encaixa.

As cores, além de serem elementos visuais, conseguem transmitir mensagens, influenciar comportamentos e atingir sentimentos, sendo componentes extremamente importantes na criação de uma publicação. Nas publicações impressas, o sistema de cores utilizado é o CMYK, sigla para Ciano, Magenta, Yellow (amarelo) e Black (preto/key), que é cor pigmento, podendo-se imprimir milhares de cores a partir das quatro acima citadas. Já as publicações digitais utilizam o sistema de cores RGB, que significa Red (vermelho), Green (verde) e Blue (azul), que é cor luz, ou seja, os raios de luzes não atingem primeiramente um objeto e aí são refletidas, elas saem direto do monitor do computador, da tela do celular etc. direto para os olhos.

Segundo Fraser e Banks (2007, p. 122),

a cor pode definir, em um relance, a natureza de uma publicação impressa. O tamanho físico de um jornal não mais é um indicador confiável de sua natureza, mas o uso da cor nos diz que, quanto mais berrante a primeira página, tanto mais inferior será o conteúdo. [...] Muitas publicações usam barras com código de cor, ou tarjas no alto de cada página para diferenciar seções editoriais, ajudando os leitores a "navegar" pelo exemplar. Ícones coloridos podem ser usados para marcar o conteúdo do tema abordado. As tintas separam boxes e barras laterais do corpo da página e blocos de cor com texto são usados comumente para atrair, chamando a atenção do leitor para o conteúdo de alguma outra página na publicação.

Assim, é preciso que as cores e a tipografia de uma publicação sejam escolhidas de maneira adequada a se encaixarem ao assunto tratado, à ideia e à reflexão que se quer provocar no leitor.

\section{Rock}

O Rock and Roll (Rock ' $n$ ' Roll, ou simplesmente rock) é um gênero musical que, apesar de ter surgido há mais de 50 anos, ainda é muito popular e consegue mover 
multidões a estádios e arenas para assistirem a shows de bandas que se dedicam ao gênero.

Segundo o Grande Dicionário Houaiss da Língua Portuguesa (2012), o Rock and Roll se define como:

música popular derivada do rhythm and blues, geralmente executada em instrumentos de amplificação eletrônica, que se caracteriza por um persistente ritmo quaternário, letras repetitivas e, eventualmente, elementos de country, música folclórica ou blues.

De acordo com Barcinski (2004), o termo "rock 'n' roll" era usado em músicas para significar "dançar" ou "fazer amor" desde o final da década de 40. No entanto, Elvis Presley, chamado até hoje de "Rei do Rock", teria apresentado o gênero musical ao mundo, principalmente por ser branco e, assim, aceitável para a América da década de 1950, tendo aberto as possibilidades para os negros que já tocavam rock. O rock é de origem negra, assim como o samba, o blues e o hip hop, e herdou desses gêneros musicais a capacidade de representar o presente por meio de suas letras.

Ainda segundo Barcinski (2004),

na época, a sociedade americana começava a abandonar preconceitos seculares. De uma certa forma, a explosão do rock simbolizou uma América nova, mais liberal, próspera e livre das dificuldades econômicas do pós-guerra. Adolescentes brancos começaram a curtir uma música antes relegada a salões de baile nos bairros negros e pobres. [...] O fato é que nenhuma outra música esteve tão sintonizada com a realidade de seu tempo quanto o rock. Desde os anos 50, ele passou a ser um espelho da sociedade, refletindo a moda, o comportamento e as atitudes dos jovens. Isso fez do rock uma música com prazo de validade, ou seja, tão ligada no "hoje" que corre o risco de sair de moda rapidamente, junto com os temas abordados (para confirmar, basta assistir a qualquer videoclipe de dez anos atrás). [...] Sendo um gênero que se alimenta sempre do novo, o rock 'n' roll gera conflito entre seus fãs. Um movimento surge como resposta ao anterior e assim por diante, numa renovação incansável.

Apesar de suas diversas vertentes como o hard rock, heavy metal, punk rock, indie rock, e tantas outras, e em virtude de muitos acreditarem que o rock, que antes passava um ideal, uma denúncia, tenha morrido, ele ainda continua presente na sociedade, mesmo que disfarçado por trás da imagem que, para alguns, as bandas atuais parecem dar mais destaque do que a música tocada.
A parte gráfica do almanaque (que pode ser encontrado na íntegra através do link: http://issuu.com/ almanaqueontherocks/docs/almanaque_on_the_rocks) teve como norte a plataforma na qual ele seria inserido. Ao observar alguns exemplos no Issuu, foi notado que, quando o zoom é utilizado pelo leitor, numa publicação que possui o seu texto restrito a um mesmo espaço e direção, o acompanhamento do que está escrito fica bem mais fácil. Nessa perspectiva, foi escolhido o formato $800 x 600$ pxl, escala do tamanho de display de tela de computador mais comum $1024 x 768 \mathrm{pxl}^{11}$ (WITH, 2008). Esse formato permite que o usuário leia o material sem ter de "passear" demais entre uma página e a outra.

Após escolhido o formato, foi necessário definir quantas colunas haveria por página. A melhor disposição que preencheu o espaço de maneira mais eficaz foi quatro colunas verticais, cada uma representando uma época específica.

Pensando em maneiras de fazer o almanaque ter apelo visual necessário para conquistar seu público, uma série de escolhas foram tomadas. Uma delas foi referente à cor; o vermelho foi escolhido por ser uma cor quente, que traz mais energia, dinamismo e emoção para o material. Porém, por ser uma cor muito chamativa, ela foi usada pontualmente no decorrer do almanaque para dar destaque aos títulos e para ser utilizada como filtro por cima de certas fotos, a fim de trazer mais pontos de cor às páginas que estavam sem vida.

Todas as fotos colocadas no almanaque foram deixadas em escala de cinza. Essa escolha foi tomada por dois motivos: primeiro, por todo o dinamismo e energia das páginas do almanaque ficar a cargo da diagramação, da fonte e da cor vermelha, imagens coloridas poderiam criar desconforto para o leitor, além de poluírem o material. O segundo motivo dessa escolha refere-se ao fato de que, por se tratar da trajetória das bandas trabalhadas, as fotografias em escala de cinza dão peso mais histórico ao material, mesmo quando as imagens são atuais.

11 Disponível em: <http://web.archive.org/web/ 20110716184450 /http://www.onestat.com/html/aboutus_pressbox51_screen_resolutions_internet.html>. Acesso em: 27 abr. $201 \overline{5}$. 
Figura 1 - fotos em escala de cinza e filtro vermelho

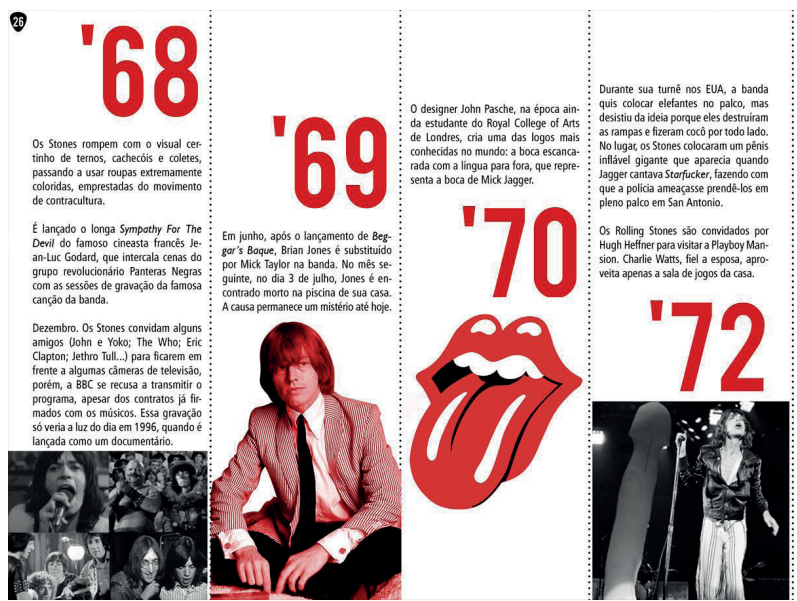

Fonte: BARRETO, Clarice da Nóbrega; MOURÃO, Débora Simões Teixeira. Almanaque On The Rocks. Brasília: 2014. p. 26. Disponível em: <http://issuu.

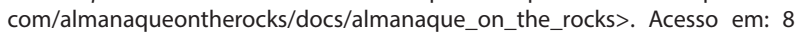
nov. 2015.

A tipia escolhida também foi pensada para melhor atender a plataforma digital. A classe bastão foi a mais indicada para o texto corrido de cada ano e da breve biografia, por conta da sua extrema funcionalidade e legibilidade. A utilização de uma tipia bastão também esteve presente nos títulos do almanaque. Apesar de também ser bastão, ou seja, não possuir serifas, essa outra tipia foi escolhida por ser mais alongada e por ter um peso mais significativo do que outras da classe bastão e, combinada com a cor vermelha, trouxe destaque aos títulos sem poluir o material.

Como os anos da trajetória de cada artista estão separados por colunas, o efeito visual estático que elas criavam teve que ser quebrado. Para isso, criou-se diagramação dinâmica entre os títulos, fazendo com que eles subam e desçam no decorrer das páginas. O material passou a ter mais jovialidade, ritmo e energia, o que se encaixa com a temática trabalhada no almanaque. Além disso, essa diagramação criou movimento de onda que remete a ondas sonoras, mais uma característica que conversa com o tema da publicação. Esse mesmo recurso de movimento pode ser notado no sumário do almanaque.

A temática do almanaque, rock, também está representada em várias outras partes do almanaque. É possível notar a sombra de duas guitarras ao fundo do sumário (que apresenta imagens verticais dos artistas, ao invés de apresentá-los por seus nomes, criando assim curiosidade no leitor que, por meio de hyperlinks, consegue ir diretamente para a primeira página do artista e descobrir de quem se trata), o elemento gráfico que envolve a numeração das páginas (uma palheta), a capa e o verso - sendo ambas dessas partes compostas por um amplificador (equipamento necessário para tocar a guitarra elétrica), uma tampa de garrafa sem especificação sobre o nome da bebida nela presente, um copo redondo de uísque que remete ao título e evidencia ao leitor do que se trata a garrafa e o nome do almanaque em si.

Figura 2 - Sumário do almanaque

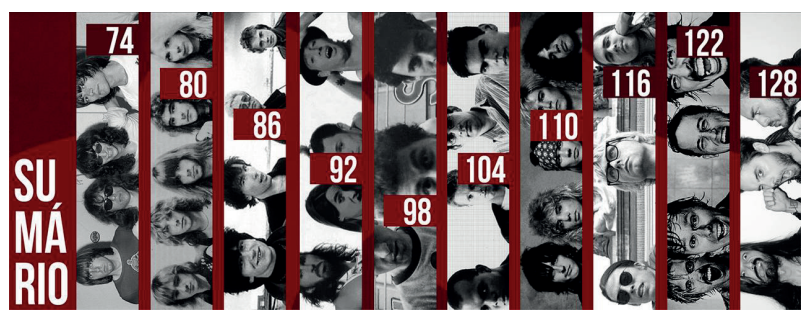

Fonte: BARRETO, Clarice da Nóbrega; MOURÃO, Débora Simões Teixeira. Almanaque On The Rocks. Brasília: 2014. p. 8-9. Disponível em: <http://issuu. com/almanaqueontherocks/docs/almanaque_on_the_rocks $>$. Acesso em: 8 nov. 2015.

O nome do almanaque surgiu a partir de um jogo de palavras. Almanaque On The Rocks, primeiramente remete a uma das opções quando se vai pedir um drinque: "on the rocks", ou seja, que ele venha com gelo. Essa terminologia que vai diretamente ao encontro do álcool e dos bares é altamente relacionável com a história da maioria dos ícones do rock e seus abusos do álcool e das drogas. $\mathrm{O}$ segundo ponto interessante é que a expressão "on" pode também ser considerada o diminutivo de online, ou seja, já mostra ao possível interessado que o produto se encontra dentro do meio digital. Além disso, quando destrinchamos a expressão inglesa, podemos considerar o "the", antes de "rocks", o artigo que falta para mostrar a importância dos músicos presentes no almanaque. A banda que está nele não é " $a$ rock star", ela é "the rock star".

A página de rosto que segue a capa apresenta a imagem de um amplificador da mesma marca que o da capa, delimitado por um círculo - elemento gráfico sempre presente no almanaque -, e com o mesmo tratamento no matiz que outras imagens do almanaque receberam. A Fender foi escolhida para aparecer no almanaque por ser uma das marcas mais emblemáticas do mundo do rock, fabricando tanto amplificadores quanto guitarras, violões e baixos. Acompanhando a imagem do amplificador, temos um background composto por um dégradé de cinza escuro com um filtro que lhe dá um ar desgastado, o mesmo filtro usado nas imagens da biografia e da capa. Ao lado esquerdo, a citação traduzida da música It's Only Rock n' Roll (But I Like It) dos Rolling Stones é apresentada estourada na página. A utilização da frase traduzida - 
e não em idioma original - foi a fim de manter sempre em mente que o almanaque foi produzido e é voltado para o público brasileiro. Além disso, a diagramação desordenada dá um ar de caos que remete ao rock ao mesmo tempo em que passa a ideia de juventude e energia a essas páginas. Outro efeito que essa diagramação trouxe, em união à cor branca usada, consistiu no redirecionamento do movimento de leitura do leitor, que, normalmente, notaria a foto do amplificador primeiro se a cor do tipo não tivesse contraste tão grande com o fundo.

Figura 3 - Página de rosto do almanaque com citação e imagem do amplificador Fender

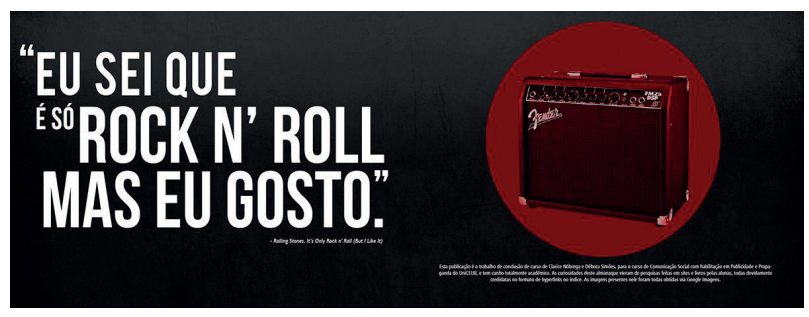

Fonte: BARRETO, Clarice da Nóbrega; MOURÃO, Débora Simões Teixeira. Almanaque On The Rocks. Brasília: 2014. p. 2-3. Disponível em: <http://issuu. com/almanaqueontherocks/docs/almanaque_on_the_rocks $>$. Acesso em: 8 nov. 2015.

Nas duas páginas que compõem a apresentação do almanaque, é possível notar o círculo branco que está presente em todas as imagens da parte biográfica de cada artista, além do filtro de matiz vermelho, as sombras bem marcadas na foto e o título da seção no tipo e na cor que os outros também estão. A escolha desse microfone específico ocorre em virtude do ar antigo e desgastado que o equipamento passa, o que representa o caos que o leitor encontrará ao ler alguns dos textos do material. Além disso, assim como as fotos em preto e branco, esse microfone traz um ar histórico que se encaixa com o formato almanaque.

Figura 4 - Apresentação do almanaque

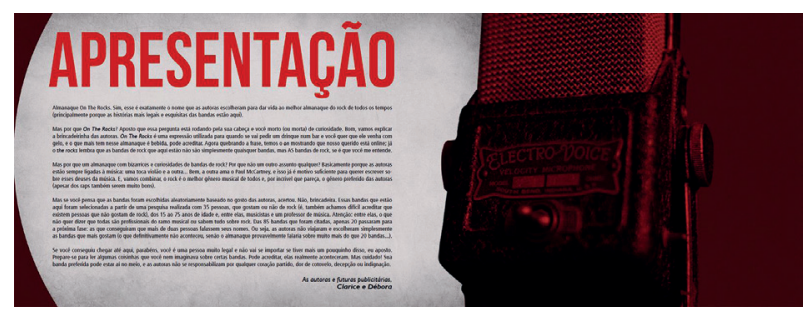

Fonte: BARRETO, Clarice da Nóbrega; MOURÃO, Débora Simões Teixeira. Almanaque On The Rocks. Brasília: 2014. p. 4-5. Disponível em: <http://issuu. com/almanaqueontherocks/docs/almanaque_on_the_rocks $>$. Acesso em: 8 nov. 2015.

A mesma justificativa pode ser utilizada nas páginas que marcam o início do índice bibliográfico. Ele é composto por duas peças de um kit de bateria e sofreu o mesmo tratamento gráfico que a imagem da apresentação. A bateria foi escolhida nessa parte por se tratar de um instrumento vital para o ritmo da música que ainda não havia sido representado nas páginas do almanaque.

Figura 5 - Índice bibliográfico do almanaque

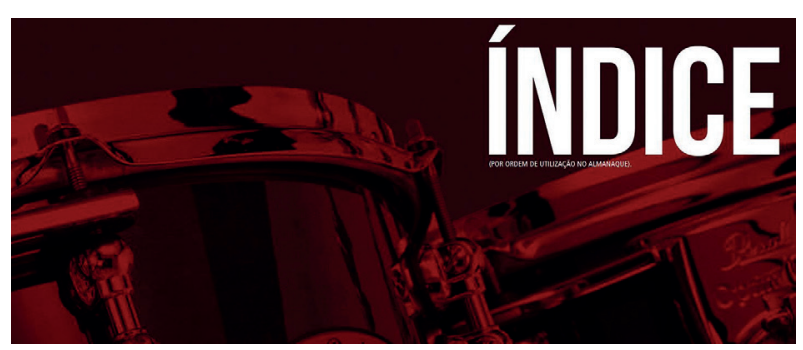

Fonte: BARRETO, Clarice da Nóbrega; MOURÃO, Débora Simões Teixeira. Almanaque On The Rocks. Brasília: 2014. p. 132-133. Disponível em: <http:// issuu.com/almanaqueontherocks/docs/almanaque_on_the_rocks >. Acesso em: 8 nov. 2015.

Com intenção de ambientar o leitor ao local onde o ícone do capítulo começou sua trajetória, foram colocadas imagens atuais das cidades nas quais cada um deles surgiu. Isso permite que a pessoa já entre no universo deles e consiga sentir o clima que rodeava cada um dos artistas, sem que essas imagens fujam do padrão gráfico do almanaque, mantendo, assim, as fortes sombras e o filtro vermelho.

Outro elemento gráfico usado para nortear o leitor foi a adição de uma pequena barra ao final da segunda página de cada uma das bandas mostrando a formação atual delas. Isso ajuda o leitor a não se perder enquanto lê o almanaque, podendo, assim, se localizar no meio das alterações que a banda sofreu e que papel cada um dos integrantes tem nela. Como a barra não poderia ter tanto destaque para não conflitar com o layout da página, foi escolhido o mesmo tipo do texto corrido, porém na cor branca. No entanto, notou-se que as biografias, aplicadas diretamente em cima das imagens, dificultavam a legibilidade do texto. Assim, foi adicionado, estourado ao final da página, um círculo que aloja essa parte escrita. Essa forma foi escolhida como a mais marcante do almanaque por estar presente no formato do copo, que se encontra tanto na capa quanto no verso da publicação. Após essa escolha, a diagramação do texto teve que ficar um pouco diferente do restante das páginas, pois a forma padrão não se adequava bem dentro do círculo, por isso, o final da frase de cada parágrafo ficou centralizado e não alinhado à esquerda, como no restante. 
Figura 6 - Biografia da banda e barra com formação atual

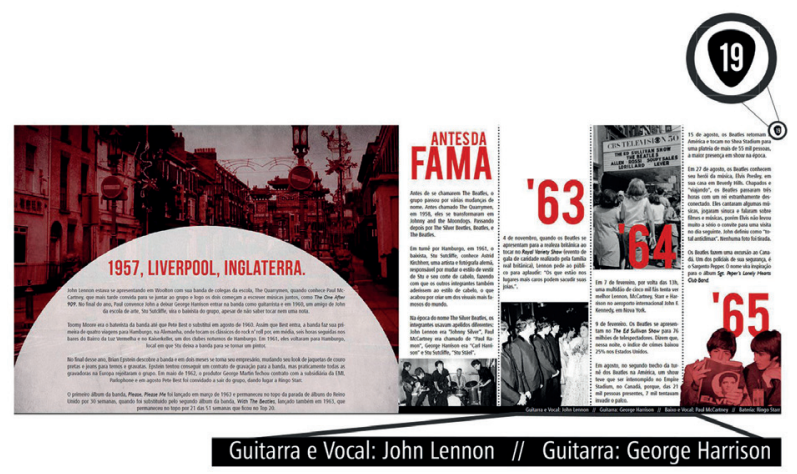

Fonte: BARRETO, Clarice da Nóbrega; MOURÃO, Débora Simões Teixeira. Almanaque On The Rocks. Brasília: 2014. p. 18-19. Disponível em: <http://issuu. com/almanaqueontherocks/docs/almanaque_on_the_rocks $>$. Acesso em: 8 nov. 2015.

A fim de aproveitar os recursos de interatividade do Issuu, foram adicionados, na página esquerda da arte que marca o capítulo de cada artista, hyperlinks que direcionam o leitor ao vídeo da canção mais ouvida do músico, de acordo com o website Vagalume.com.br. Os vídeos "linkados" são de shows ou videoclipes dos artistas, escolhidos para aproximar o leitor do artista.

Além disso, também foram adicionados hyperlinks para vídeos de alguns momentos citados nos textos do almanaque, possibilitando que o leitor veja o que aconteceu ao invés de ter apenas que imaginar, aproximando-o, assim, da história relatada e servindo de complemento para as imagens de certos acontecimentos.

A ideia inicial de manter os hyperlinks evidentes ao longo dos textos teve que ser descartada, tornando-se necessária a criação de índice bibliográfico ao final do almanaque, uma vez que, após o primeiro teste de postagem da publicação na plataforma, notou-se que os hyperlinks presentes no almanaque ficariam delimitados por um quadrado azul pontilhado, devido a uma atualização do Issuu. Isso causou interferência negativa no efeito visual que as páginas do almanaque têm. Logo, para contornar esse problema, foi decidido criar um índice bibliográfico ao final do produto com todos os websites e livros utilizados na pesquisa, organizados por ordem de aparecimento no capítulo (tanto para dar crédito às pessoas responsáveis por descobrir a história, como também dar espaço para o leitor se aprofundar mais em algum capítulo que lhe seja de interesse). Dessa maneira, o índice foi criado da forma mais limpa possível para não conflitar com os elementos gráficos de marcação de hyperlinks que o Issuu coloca.

$\mathrm{Na}$ confecção desse índice, decidiu-se manter a fonte das fotos de fora, já que, como foram utilizadas inúmeras imagens, seria necessário elaborar um índice muito extenso que comportasse todas as referências, o que não foi considerado como boa opção pelas autoras, que preferiram mencionar na terceira página do almanaque (a que apresenta o amplificador dentro do círculo vermelho) que as imagens presentes no produto foram obtidas via Google Imagens.

O produto final foi fechado com 144 páginas, 246 hyperlinks para referências utilizadas no almanaque, 20 hyperlinks que permitem que o leitor vá do sumário até a página que deseja, e 53 hyperlinks em imagens que direcionam o leitor para vídeos que complementam o que é relatado.

\section{Considerações finais}

No desenvolvimento do almanaque, desde a escolha do produto até o final de sua diagramação, foi possível perceber que, apesar de o formato almanaque realmente ter sido muito utilizado e hoje estar sendo "esquecido", há ainda chances de se revitalizá-lo disponibilizando-o em meio digital, em que o custo é menor, uma vez que não é preciso imprimi-lo; há a possibilidade de se ter um feedback direto e imediato do público; a publicação pode ser alterada ou retirada a qualquer momento. Além disso, o meio digital permite a interatividade, seja essa entre usuários a partir de comentários, compartilhamentos etc., ou a partir de hyperlinks que dão aos usuários inúmeras possibilidades, como a compra de um livro utilizado como referência na publicação, o acesso a um portal especializado em determinado assunto e afins.

Em relação ao assunto abordado no almanaque, apesar de existirem inúmeras curiosidades e histórias sobre bandas de rock em websites, blogs, fóruns, há a enorme dificuldade de acesso a informações verossímeis e datadas sobre essas bandas, uma vez que um almanaque aborda um assunto a partir de uma linha do tempo em ordem cronológica. Além disso, talvez um dos maiores desafios tenha sido tentar encontrar essas informações sem saltar de um ano para cinco à frente e conseguir organizá-las em um curto espaço de tempo.

A resposta à questão proposta no trabalho, "Como criar um produto gráfico que tem seu formato esgotado a partir de um assunto já muito explorado?”, é, justamente, a inserção do almanaque numa plataforma digital e a utilização do assunto, curiosidades das bandas de rock, visto 
por um outro lado, que mostra a realidade dos artistas que, muitas vezes, são tratados como deuses.

O objetivo de criar um produto gráfico que consiga trazer as características do formato tradicional do almanaque para o digital, de maneira atrativa para os usuários da plataforma, e que consiga dar nova roupagem numa temática que está saturada, por meio de uma nova linha de abordagem, foi alcançado a partir da própria criação do almanaque. A nova roupagem relaciona-se à modernidade trazida para um formato clássico, o almanaque impresso, conseguida por meio do uso de uma plataforma digital e uma diagramação dinâmica. Essa modernidade também foi conquistada com a utilização de ferramentas da plataforma (hyperlinks, curtidas, compartilhamentos) que garantem interatividade ao produto. Já a nova linha de abordagem refere-se a um lado menos conhecido (curiosidades) dos artistas escolhidos trazido no almanaque, mostrando a ideia de que nem tudo é o que parece, ou seja, nem sempre a imagem que um artista passa é a verdadeira e representa o que ele realmente é.

Assim, foi possível reconhecer que a produção de um almanaque, desde a escolha do assunto abordado até sua publicação, constitui trabalho que exige tempo do autor para que seja possível reunir informações confiáveis e paciência para reler tudo o que foi escrito, excluir o que não é mais necessário e organizar todo o material colhido e escrito da forma mais clara possível; e que, no desenvolvimento de qualquer produto de comunicação é preciso estar realmente atento a todas as escolhas, seja de cor, tipografia, fotografia, layout, tipo de linguagem utilizada, uma vez que, a partir dele, é passada uma mensagem ao espectador tanto pelo conteúdo quanto pelo formato.

\section{Referências}

BARCINSKI, André. Rock 'n' roll: um, dois, três, quatro! Revista Superinteressante, São Paulo, n. 205, out. 2004. Disponível em: <http://super.abril.com.br/cultura/rock-n-roll-dois-quatro-444901.shtml $>$. Acesso em: 26 abr. 2015.

COLLARO, Antônio Celso. Produção gráfica: arte e técnica na direção de arte. 2. ed. São Paulo: Pearson Prentice Hall, 2012.

CONECTANDO conteúdo às pessoas. [2015?]. Disponível em: <https://issuu.com/about>. Acesso em: 04 nov. 2015.
FRASER, Tom; BANKS, Adam. O guia completo da cor. 2. ed. São Paulo: Senac, 2007.

GRANDE dicionário Houaiss da língua portuguesa. Disponível em: <http://houaiss.uol.com.br>. Acesso em: 26 abr. 2015.

HASLAM, Andrew. O livro e o designer II: como criar e produzir livros. 2. ed. São Paulo: Rosari, 2010.

HENDEL, Richard. O design do livro. São Paulo: Ateliê, 2003.

HURLBURT, Allen. Layout: o design da página impressa. São Paulo: Nobel, 2002.

MARCONI, Marina de Andrade; LAKATOS, Eva Maria. Fundamentos de metodologia científica. 7. ed. São Paulo: Atlas, 2010.

MULHOLLAND, Garry. Popcorn: o almanaque dos filmes do rock. São Paulo: Seoman, 2011. Disponível em: $<$ http://issuu.com/grupoeditorialpensamento/docs/popcorn>. Acesso em: 04 nov. 2015.

PRODANOV, C. C.; FREITAS, E. C. Metodologia do trabalho científico: métodos e técnicas de pesquisa e do trabalho acadêmico. 2. ed. Novo Hamburgo: FEEVALE, 2013.

RADFAHRER, Luli. Enciclopédia da nuvem: 100 oportunidades e 500 ferramentas online para inspirar e expandir seus negócios. Rio de Janeiro: Campus, 2012.

SINDICATO NACIONAL DOS EDITORES DE LIVROS. Produção e vendas do setor editorial brasileiro. 2013. Disponível em: <http://www.snel.org.br/dados-do-setor/producao-e-vendas-do-setor-editorial-brasileiro/>. Acesso em: 4 nov. 2015.

WITH our web analytics we help more than 75,000 customers. 2008. Disponível em: <http://web.archive.org/ web/20110716184450/http://www.onestat.com/html/ aboutus_pressbox51_screen_resolutions_internet.html >. Acesso em: 4 nov. 2015. 